\title{
CORPORATE CULTURE AND WRITING: THE EVOLUTION OF THE WRITTEN DOCUMENT
}

\author{
ROBERT BUCHAN \\ DISTRICT OF CAMPBELL RIVER, BRITISH COLUMBIA
}

\begin{abstract}
This article is an ethnographic study of the author's writing processes in three public sector organizations. The analysis shows how various structural variables such as the writer's corporate position and the complexity of the corporate form interact with such operational variables as management style and audience interpretation in the production of a document in each corporate culture.
\end{abstract}

\section{INTRODUCTION}

Corporate writing has been studied in two principal ways--by survey and by ethnographic case study. This paper is an ethnographic enquiry into corporate writing based on my experience in three public sector jobs. Lipson (1986, 1987) and Lutz (1986) have stressed the importance of understanding the role of corporate culture in the writing process. I will identify and discuss some of the specific corporate cultural variables which I have found to affect the writing process.

I am defining corporate culture as an organization's internal structure and conventions. Although it can include everything from how one dresses in the office to coffee room rituals, I will discuss only some of the cultural variables which directly affect the writing process. Corporate culture will vary from group to group depending on the specific combination of cultural variables. These include structural variables such as the writer's corporate position and the complexity of the corporate form. Operational 
variables include management style, lexicon standards, format standards, stakeholder input, audience interpretation, the audience, and the document's purpose.

\section{CASE ONE: LANGLEY TOWNSHIP, BRITISH COLUMBIA}

\section{Corporate Context}

In Langley Township, a municipality of approximately 65,000, my position within the Community Development Department was as an entry level professional, planning technician. My primary function was to evaluate and report on land development applications. Figure 1 illustrates my hierarchical position with the department and displays
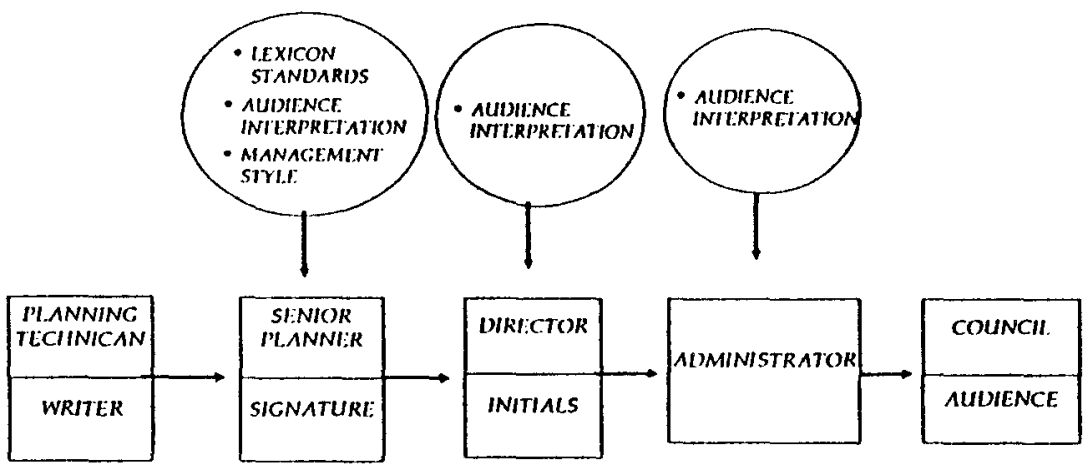

Structural Variables

Writer's Corporate Position: Removed/Distant from Audience

Corporate Form: Complex (Format Standards)

Operational Variables

Lexicon Standards

Audience Intcrpretation

Management Style

Figure 1. Variables Affecting the Document: Case 1 
the document's path to the ultimate audience. The reports which I wrote would go to the Senior Planner for approval and signature, then to the Director for approval and initials, then to the Administrator, and finally to the ultimate audience, the Mayor and Council.

Reports generally ranged from four to six pages in length and were prepared according to strict and detailed document format standards (see Figure 2).

To:

From:

Presented:

Subject

Administrator's Comments/Recommendations:

Recommendation:

Reference Data:

Background:

Comments:

Policy Considerations:

Conclusion:
Report No:

File No:

Doc. No.: 
section, - even graphics, from past documents and incorporates them into new proposals, reports and correspondence" (1983). Within the Langley context, the use of the last best example could be described as "safe writing" because the examples were proven to have provided the necessary communication to Council without creating any problems. Such problems could include confusing Council by using new terms they do not understand, or causing Council to raise questions not germane to the development application and to overlook pertinent issues.

Changes to the Document

My junior position in the corporate structure dictated that I could exercise little creativity. Also, my junior position created an information gap between senior management and myself. Senior management were aware of a broader range of issues such as historical precedents, the interests of other departments, and legal implications, and management was also the source of new departmental policies. This information gap frequently resulted in my reports being redrafted at senior levels. Much of the document revision at senior levels derived from interpretation of the audience. Senior managements greater familiarity with the ultimate audience enabled a greater degree of audience adaptation.

Cronin's findings in his 1983 study of the writing requirements in a large construction firm have strong parallels with my Langley experience. Cronin reports that entry level professionals are intentionally separated from the clients (audience) because their general lack of experience and ignorance of the legal implications of what they write could seriously damage the company/client relations. All reports would go to senior managers for their approval and signature.

In the Langley case the two senior planners had significantly different management styles. One would put considerable effort into the rewriting of documents until he was comfortable that the style and content would be acceptable to the Director and Administrator. He would revise my reports and revise again his modifications until the ultimate report bore little resemblance to my original version. The other manager tended to be satisfied with much of my writing as long as the appropriate last best examples were used. I preferred the style of the latter senior 
planner as I felt a greater sense of ownership and pride in the report when I knew that some of my original composition would remain in the report.

\section{CASE TWO: DISTRICT OF CAMPBELL RIVER, BRITISH COLUMBIA}

\section{Corporate Context}

In Campbell River, a municipality of 25,000 , my current position as Assistant Planner has a similar place in the hierarchy to that of the Senior Planner position in Langley Township (see Figure 3). Both of these positions report directly to the Department Directors and both have direct interactions with Council and other Municipal Department heads.

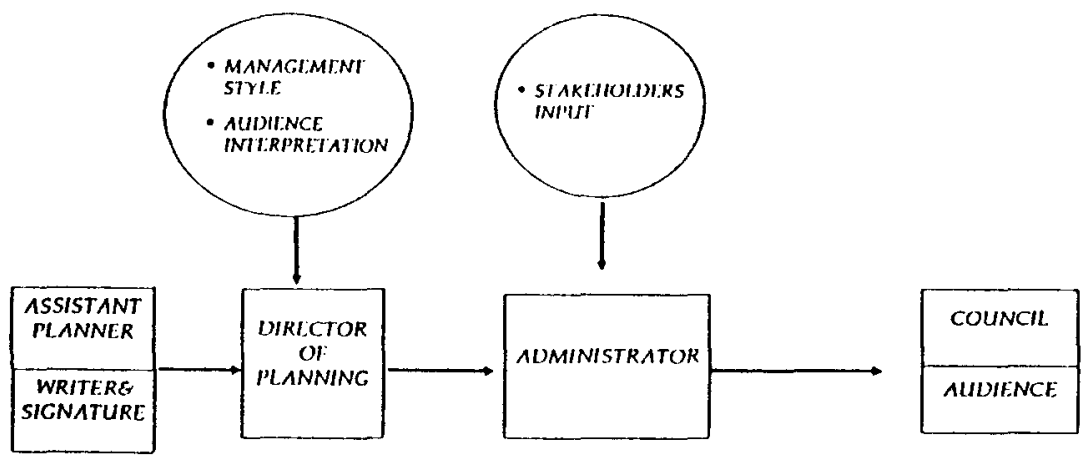

Structural Variables

Writer's Corporate Position: Close to Audience

Corporate Form: Simple

Operational Variables

Management Style: Low Intervention

Audience Interprelation

Stakeholder Input

Figure 3. Variables Affecting the Document: Case 2 
I receive, evaluate, and report on development applications and conduct planning studies, prepare plans, and prepare policy documents. All reports are directed to the Administrator who may direct them to Municipal Council for its consideration.

This corporate culture differs from the Langley culture in many ways. There are, for example, fewer format standards. In addition to the basic report components (purpose, background, comments, and recommendations), I may include any number of additional components. There is also no specified corporate lexicon. The director's principle for report writing is simply that the report must clearly communicate to its audience.

\section{Changes to the Document}

Because of my position in the hierarchy, I am aware of the needs of other departments and also have a better understanding of the report's audiences. Provided that I have gauged the audience correctly, there is less need for rewriting than in Langley.

The management style of my superior is also significantly different from that of my superiors in Langley. The Director of Planning in Campbell River generally makes changes only when he adds historical context, or thinks that further explanation is needed. Knowing that there will be no changes to writing style, I take more care in composing and have greater pride in the final document.

One important reason for revising documents that I did not encounter in the Langley case is the necessity to secure the agreement from other departments that are stakeholders. Because some planning proposals can affect the responsibilities belonging to these departments. A planning proposal can often have significant financial implications that require the finance department's endorsement. Take, for example, a program to plant trees within the boulevards of municipal roads. These plantings will require funds for on-going maintenance. Also, given that utilities are located in municipal roadways, the Engineering and Public Works Departments need to ensure that tree plantings can be coordinated with the location of underground utilities. 


\section{CASE THREE: PROPERTY DEVELOPMENT SECTION OF PUBLIC WORKS CANADA, PACIFIC REGION}

\section{Corporate Context}

In the third corporate context, in my position as Property Development Officer (PDO) in Public Works Canada, I prepared "Area Screening" reports (see Figure 4). These reports commissioned annually by the Treasury Board's Bureau of Real Property management (BRPM),

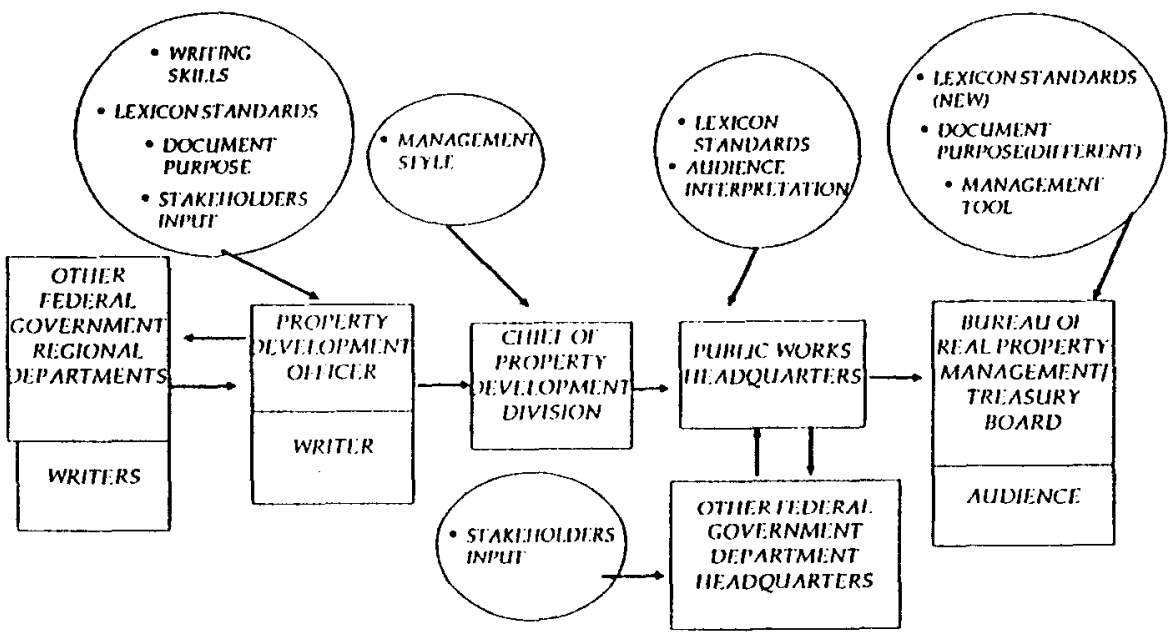

\section{Structural Variables}

Writer's Corporale Position: Removed/Distant from Audience

Corporate Form: Complex

\section{Operational Variables}

Writing Skills

Lexicon Standards

Document Purpose

Management Style: Laissez-Faire

Audience Interprctation

Document Purpose

Stakeholder Input

Figure 4. Variables Affecting the Document: Case 3 
identify and evaluate the use of Federal properties on a regional basis throughout Canada and are used by the Bureau as a management tool for federal properties. The reports serve to identify properties which are not being fully utilized, are not required or which may have environmental concerns. Although detailed evaluations are conducted for each property, the intent is only to identify problems in a general fashion. Given that these area screening reports are prepared for regions across Canada and that information is supplied by a large number of federal agencies, there is a need for the reports to present information in a consistent manner. Therefore, the area screening documents have highly structured and standardized formats.

The major stakeholders in the evaluation of the federal properties are the federal departments which have custody of real property for their mandated use and the Bureau of Real Property Management, which is concerned that federal property be efficiently managed and used and be environmentally compatible. Given that the federal departments tend to be rather proprietary with their land inventory, there is a strong possibility for an adversarial relationship between the federal departments and the Bureau.

In order to minimize the adversarial potential, a standard language has been developed for the analysis components of the report. Phrases and wording are used to soften any negative evaluation. For example, instead of concluding that a property is not required by a federal department to meet its program requirements, the report might be phrased as follows:

"Future program related development needs should be specified if land retention is required. Monitor".

This statement identifies a problem, but does not conclude that the property is surplus and should be disposed of. It should be noted that although the standardized phrases do have to be used, it is my experience that the particular repertoire of phrases changes with time, sometimes too rapidly. 
As a Property Development Officer I was responsible for collecting the property information from all other federal government departments which have custody of property within the study area. This information was supplied to me in written form in standardized formats which were inserted directly into the area screening document.

\section{Changes to the Document}

Given the complex corporate structure and my corporate position somewhat removed from the document's audience, there was plenty of opportunity for changes to be made.

The first level at which documents were revised was between the regional offices and me. Changes could be simply due to the poor writing skills of the federal officers supplying information. Occasionally information necessary for analyzing property use was not provided. As this would defeat the document's purpose, I had to work with the other federal officer until his or her submission included the required data. Any rewriting, however, had to be approved by the other federal departments who had high stakes in what was reported and how it was reported because one of the potential results of the information was the loss of custody of the property.

When I had completed a draft of the document, it was passed to the regional chief of property development. The Chief in the Pacific region office had a very laissez-faire management style so no document changes would result at that stage.

The documents were then passed on to Public Works Canada (PWC) Headquarters in Ottawa. There were three reasons for rewriting at this stage - lexicon standards, audience interpretation, and stakeholder input.

PWC headquarters' role in producing the area screening documents was to ensure that each document (as many as six in each year) used the standardized language. Given the importance of the document to each federal department involved, the pertinent sections had to be signed off by the headquarters of each department. This process would often result 
in additional changes either because the wording or conclusion would be deemed too strong or because additional information would be provided which would change recommendations.

The closeness of headquarters to the document's ultimate audience would also cause some rewriting. Headquarters would be more familiar with the changes in the audience's information needs and agenda and would alter the documents accordingly. In the three years I spent in this organization, information needs changes at least once a year.

The document's audience was the last source of rewriting. This source was not a factor in either of the municipal cases. However, because the Treasury Board's Bureau of Real Property Management were active managers (in contrast to the primarily decision making role of municipal Council), they had a greater interest in what the documents contained. If, for example, there were several strong recommendations for property disposition, it was not uncommon for the Bureau to soften the recommendations of the less important properties and then focus their attention on the more important properties which had strong recommendations. It was felt that if the strong recommendations were left in for all properties, the Bureau's effectiveness might be diluted by spreading their resources around too many management activities.

\section{CONCLUSION}

A number of lessons can be drawn from my experiences in these three corporate settings. Perhaps the most important point for students of technical writing is that their documents may incur a significant amount of revision. The principal reason for revision is that the documents are owned by the corporation and have to facilitate its goals. The information contained in documents can have significant implications and liabilities. This non-neutrality of information requires a good amount of input and agreement from stakeholders within the corporation. By simply minimizing their intervention in their subordinate's writing style, managers may provide for a greater degree of employee satisfaction and concurrently a greater effort in writing. The challenge posed to managers, of course, is achieving the balance of minimizing intervention 
while still achieving the necessary control over the information contained in the document.

My analysis of these three cases may suggest an approach to understanding each new corporate culture one comes to write for. The writing professional may more quickly be able to understand the writing practices in a corporation by identifying the specific variables at work. I have broadly grouped these variables under two headings - structural and operational. Structural variables include the hierarchical structure in the corporation and the writer's position within the hierarchy. The more complex the hierarchy and the further down the writer's position in that hierarchy, the more likely it will be that documents will be revised. This rewriting process may be understood as the document's evolution in that it may change so much that it ends up quite different from the original draft. In the Langley and Public Works Canada case, the writing process is recursive. In contrast, the simpler corporate hierarchy of the Campbell River corporate culture enables a more linear writing process. Operational Variables include management style, lexicon standards, format standards, stakeholder input, audience interpretation, the audience itself, and the document's purpose. Each of these variables can have different expressions and in combination create a unique corporate culture. The management style in the Regional Office of the Property Development Section of Public Works Canada, for example, was particular laissez-faire, even though the corporate structure was the most complex of the three case studies.

\section{REFERENCES}

CRONIN, Frank C. (1983). "Writing Requirements in a Large Construction Firm, The Technical Writing Teacher, Vol. X, No. 2, 81-85.

LIPSON, Carol (1987). "Teaching Students to 'Real' Culture in the Workplace: Reply to Gerald Parsons, The Technical Writing Teacher, Vol. XIV, No. 2, 267-270. 
LIPSON, Carol (1986. "Technical Communication: The Cultural Context, The Technical Writing Teacher, Vol. XIII, No. 3, 318-323.

LUTZ, Jean (1986). "The Influence of Organizations on Writer's Texts and Training", The Technical Writing Teacher, Vol. XIII, No. 2, 187-190.

SELZER, Jack (1983). "The Composing Process of an Engineer, College Composition and Communication, Vol. 34, No. 2, 178-187.

Robert Buchan is Assistant Planner with the District of Campbell River in British Columbia. 